\title{
Quantitative risk analysis procedure for economic project sustainability.
}

\section{Procedimiento de análisis cuantitativo de riesgos para la sostenibilidad del proyecto económico}

\author{
Jithin Arakkatt Shaji \\ Lead Planner Jacobs, Etihad Rail Project, Dubai, United Arab Emirates \\ Corresponding author mail id: jithinashaji@gmail.com
}

\begin{abstract}
The paper briefly explains the importance of quantitative procedures of risk analysis in large and medium scale projects for the sustenance of project economic sustainability. Globally, several construction projects are being descoped and tend to close out before attaining the initial project deliverables due to cost and schedule overruns. The quantitative methods can sieve the key factors and forecast the tangible impacts that can lead to schedule or cost variance in a project. It can guide the project stakeholders for timely decision making and mitigate the risks associated to achieve the project goals. Today, the quantitative methods are pivotal to analyze the impacts of Covid-19 crises in Construction industry which are increasingly apparent.
\end{abstract}

Keywords- Project economic sustainability, Risk analysis, Quantitative methods.

\section{RESUMEN}

El artículo explica brevemente la importancia de los procedimientos cuantitativos de análisis de riesgos en proyectos de gran y mediana escala para el sustento de la sostenibilidad económica del proyecto. A nivel mundial, se están diseñando varios proyectos de construcción y tienden a cerrarse antes de alcanzar los entregables del proyecto inicial debido a los costos y los retrasos en el cronograma. Los métodos cuantitativos pueden tamizar los factores clave y pronosticar los impactos tangibles que pueden conducir a variaciones en el cronograma o en los costos de un proyecto. Puede guiar a las partes interesadas del proyecto para la toma de decisiones oportuna y mitigar los riesgos asociados para lograr los objetivos del proyecto. Hoy en día, los métodos cuantitativos son fundamentales para analizar los impactos de las crisis de Covid-19 en la industria de la construcción, que son cada vez más evidentes.

Palabras clave: sostenibilidad económica del proyecto, análisis de riesgos, métodos cuantitativos 
Sustainability, Agri, Food and Environmental Research, (ISSN: 0719-3726), 10(X), 2022: http://dx.doi.org/

\section{INTRODUCTION}

The project sustainability is redundantly being arbitrated with environmental sustainability however, the project sustainability is attributed by political, legal, economic, environmental, cultural and educational aspects. The United Nations (Brundtland Commission) has defined sustainable development as "development that meets the needs of the present without compromising the ability of future generations to meet their own needs" (PMBOK Guide, 2017). Nevertheless, the description varies with respect to the context and assumptions on which a project is being developed. In this paper, the economic sustainability of a project is considered, and a review is made on the quantitative methods of risk analysis in terms of project schedule and cost risks (PMBOK Guide, 2017).

The project risk management can be broadly performed in following steps (AugstinPurnus and Constanta-Nicoleta Bodea, 2013):

- Establish risk management plan

- Risk identification

- Risk analysis - Qualitative and Quantitative

- Plan and implement risk response

- Monitor and control risk

The risk analysis is the process to identify the uncertainties that can potentially undermine the project deliverables and even the business case. There are two aspects of risk analysis - qualitative and quantitative risk analysis. In qualitative analysis, the risks are being prioritized with a rating ranging from zero to one for further action and tangible analysis. The focus will be laid on high rated risk and decisions will be taken for its priority. The quantitative analysis statistically quantifies the impacts of identified risks in terms of schedule and cost. This figurative analysis can call for urgent decision making since statistical values can significantly rate the project success and failure. Apparently, a timely decision making by the key project stakeholders can widely mitigate the risks to a greater extent (D. L. Andersen, 2011).

\section{QUANTITATIVE METHODS OF RISK ANALYSIS}

The risk and uncertainties associated with a project changes with time. As the project advances through the initiation phase to the close-out phase the degree of risks vary substantially. An accurate risk identification at the initiation and planning phase will be 
Sustainability, Agri, Food and Environmental Research, (ISSN: 0719-3726), 10(X), 2022: http://dx.doi.org/

the determining factor for the overall project life cycle. Therefore, prefeasibility stage of a project will be having more uncertainties than a project which is under the execution phase. In risk analysis, the impacts are quantified in terms of time (schedule) and cost. Therefore, the quantitative methods of risk analysis are classified as quantitative schedule risk analysis (QSRA) and quantitative cost risk analysis (QCRA).

\section{QUANTITATIVE SCHEDULE RISK ANALYSIS (QSRA)}

The QSRA is used to understand the risk associated with the time and it helps the project team to decide whether a particular risk must prioritize and mitigate in order to complete the project as scheduled. In this method, a mathematical model or iteration is applied to the project schedule with a specific software. The iterations will simulate how the risk will impact the schedule and gives a forecast completion date to the overall project. The results will be a confidence factor to the Project team on how the project can be completed with impacts from the risk and what level of response factor the team should adopt to mitigate the risk on a timely manner. The QSRA will enable the project team to represent the uncertainties in the project to the stakeholders by enumerating the schedule impacts to the resilience allowed in the project schedule.

The risk events are established in the project schedule with assumptions and sub activities are added to demonstrate the impact. The simulation in the software is performed based on the agreed project risk management plan. The output of the iterations will report the impact of risk events to the project schedule. The stakeholders can identity the risks with highest impact and call for necessary risk mitigation plans. Therefore, the Schedule analysis gives an approximate estimate of the extent to which a project can be delayed due to a risk event which is called the anticipated time for project completion. The frequency of schedule risk analysis can be based on the complexity of the project and dependency of project progress on the risks which are identified. On a medium scale project, the frequency of analysis can vary from quarterly to half yearly basis. The responsibility of the analysis is on Project Risk Manager or in his absence to the Project Manager.

The QSRA on a Project can be successful only if the project team is qualified enough to understand and value the risk management plan. It should have a complete buy in from the project management and leadership team. The project stakeholders should have an open mind approach to the inputs and results of QSRA report and should be identified as an integrated method of project risk management. The overall culture of the project team will be the key to perform and succeed with QSRA (CIOB, 2008).

The schedule risk analysis uses the following methods for risk qualification (Jurie Steyn,2018):

- Critical Path Method (CPM)

- Program Evaluation Review Technique (PERT) 
Sustainability, Agri, Food and Environmental Research, (ISSN: 0719-3726), 10(X), 2022: http://dx.doi.org/

- Fault Tree Analysis

- Monte Carlo Simulation

The software used for the analysis are:

- MS Project with @RISK or Risk+

- Primavera Risk Analysis with Monte Carlo or Delteck Acumen Risk The inputs for the analysis are:

- The agreed project baseline programme

- Risk mapping from the qualitative risk analysis

- Assumption log

- Project schedule logic

Following are the methodologies used for the analysis (Nikki Underwood, 2018):

- Demonstrate and agree with the project team on the procedure to model the risks identified in the schedule and the key project milestones to be considered

- Progress the first schedule run and present the modelling report with the project team in a brain storming workshop

- Review the findings from the first cut iteration and agree with the delivery team on the impacts and schedule variance, alter the assumptions if the findings are unrealistic and not accepted by the project team

- Reschedule the run with agreed assumptions and changes made of the first analysis report

- Secure the project buy in for the final analysis report and present to the higher management to material the decision making

QSRA report consist of the following:

- Narrative report on the procedure

- Assumptions log

- Modelling inputs and outputs

- Report on project schedule analysis

- Updated risk register

- Risk mapping sheet

- Summary of the findings

- Risk adjusted schedule

- Conclusion and recommendation

The output will help the project team to decide on which risk being mitigated, which risks being managed with right monitoring tools and on which risks being given the tolerance (Jurie Steyn, 2018). 
Sustainability, Agri, Food and Environmental Research, (ISSN: 0719-3726), 10(X), 2022: http://dx.doi.org/

\section{QUANTITATIVE COST RISK ANALYSIS (QCRA)}

The QCRA is used to understand the risk associated with the cost and it helps the team to decide whether a particular risk must prioritize or mitigate in order to complete the project as per the agreed budget. The method uses the updated project risk register with probabilistic estimates on the occurrence of identified risks along with the cost impact values. The likelihood of the impacts is generally expressed as a three-point estimate as low, medium and high. The cost values are generally from expert judgement or parametric analysis. Further, the simulations are made based on the Monte Carlo method or the Three Scenario Approach. The Monte Carlo simulation is more accurate and requires more time and effort to perform. The Three Scenario method is a semi-probabilistic method and uses cost buffers from reliable estimates and evaluate the reasonable probabilities to meet the target (Nikki Underwood, 2018).

The QCRA identifies the cumulative frequency and probability of non-exceedance or probability of exceedance of the risks to analyze the cost impact of a particular risk. The range of uncertainty is expressed in terms of probability distribution as P10, P50 and P90, where " $P$ " represents Percentile. The deterministic cost value is replaced by the probability distribution resulting in a potential range of outcome. A cost value is being generated for each of the distribution and the model is performed repeatedly for thousand and more times. Every time the value will be recorded and reported in a probability distribution format. On completion the statistics are studied to analyze the probability of occurrence. Based on the nature of risks and the results from the iteration the cost impact can be analyzed for the project with respect to the probability of occurrence. This can enable the risk owner or the Project Manager to evaluate the measures of mitigation and thereby reduce the impacts to avoid cost overruns (PMBOK Guide, 2017).

The frequency of QCRA analysis in a medium to large scale Project can be on a quarterly basis however it can vary on the intensity of risk identification. The output of QCRA gives the anticipated final cost for the project which is updated in the project cash flow and cost S-curves are adjusted to demonstrate the percentile estimates (P10, P50 and P90). The percentile values can vary based on the agreements reached in the QCRA procedure and commercial conditions in the project contract document. The anticipated final cost is a dynamic estimate which reflects the realistic assessment of the cost overruns in a project on every QCRA update (D. Cooper et. al., 2014).

The cost risk analysis uses the following methods for risk qualification:

- Monte Carlo simulation

- Three Scenario method

The software used for the analysis are:

- PRISM 
Sustainability, Agri, Food and Environmental Research, (ISSN: 0719-3726), 10(X), 2022: http://dx.doi.org/

- $\quad$ ARM - Active Risk Manager

MS Excel with @RISK (Nikki Underwood, 2018)

The inputs for the analysis are:

- Updated risk register with cost estimates and probability list of an event

- Risk mapping from the qualitative risk analysis

- Assumption log (C. Chapman and S. Ward, 2003)

Following are the methodologies followed for the analysis:

- The risk register is updated along with the project team - Project Manager \& Risk Manager

- Assumptions and cost values for occurrence are agreed with the project team

- The risks are modelled for probabilities from the first model run

- The draft report is discussed with the project team in a brain storming workshop

- The feedback from the team is incorporated in the final report

- The risk exposure is combined with the overall project or programme risk

- The anticipated final cost is presented to the senior management and material the mitigation actions to minimize the impact (AugstinPurnus and Constanta-Nicoleta Bodea, 2013)

QCRA report consist of the following: (C. Chapman and S. Ward, 2003)

- Narrative report on the procedure

- Updated risk register

- Assumptions log

- Modelling inputs and outputs

- Risk mapping sheet

- Summary of the findings

- Risk adjusted cash flow

- Cash flow S-curves updated with percentile estimate

- Conclusion and recommendation

The QCRA output will help the project team to decide on which risk being mitigated, which risks being managed with right monitoring tools and on which risks being given the tolerance to complete the project within budget without the project sponsor spend additional contingency allowances. (V. Liberzon \& B. P. Souza Mello, B. P., 2011).

\section{CONCLUSION}

The schedule and cost overruns are the key factors to determine the economic project sustainability. The quantitative risk analysis helps to numerically estimate the probability of a project to meet its schedule and cost objectives. The results of the analysis help the project delivery team to communicate the realistic project status when the 
Sustainability, Agri, Food and Environmental Research, (ISSN: 0719-3726), 10(X), 2022: http://dx.doi.org/

stakeholders argue for unrealistic project expectations. Therefore, the quantitative risk analysis can drive the projects to become economically sustainable in this challenging environment and economic transition to the new normal (D. Cooper et. al., 2014).

\section{REFERENCES}

Andersen, D. L. (2011). Project Risk management - Inside Out: How to cope with complexity generated risk, in: Future Trends in Project, Programme and Portfolio Management, Proceedings International Expert Seminar in Zurich, IPMA, ISBN 9783-9523891-2-6.

Augstin Purnus and Constanta-Nicoleta Bodea, Procedia - Social and Behavioral Science 74 (2013), 144 - 153, Published by Elsevier Ltd.

Chapman, C., \& Ward, S. (2003), Project Risk Management, Processes, Techniques and Insights, Second edition, John Wiley \& Sons Ltd.

CIOB (2008), Managing Risk of Delayed Completion in the 21st Century, Chartered Institute of Building, 52-53.

Cooper, D., Bosnich, P., Grey, S., Purdy, G., Raymond, G., Walker, P. \& Wood, M. (2014), Project risk management guidelines; managing risk with ISO31000 and IEC 62198, 2nd ed. John Wiley \& Sons, Ltd. Chichester, West Sussex.

Jurie Steyn (2018), Quantitative Risk Analysis for Projects, owerteamconsult.com.

Liberzon, V., \& Souza Mello, B. P. (2011), Success Driven Project Management (SDPM) Approach to Project Planning and Performance Analysis, The 8th Annual PMI College of Scheduling, San Francisco.

Nikki Underwood (2018), Qualitative Cost Risk Assessment, Published in Crossrail Learning Legacy.

PMI (Project Management Institute, Inc.) (2017), A guide to the project management body of knowledge (PMBOK Guide), 6th ed. PMI Book Service Center, Atlanta.

Received: $15^{\text {th }}$ February 2021; Accepted: $20^{\text {th }}$ March 2021; First distributed: $30^{\text {th }}$ March 2021 